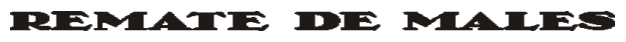

Campinas-SP, v.40, n.2, pp. 501-510, jul./dez. 2020

\title{
ESTADO DE GRAÇA
}

\section{STATE OF GRACE}

\section{Manoel Ricardo de Lima ${ }^{1}$}

Resumo: Este artigo parte da crítica elaborada por Pier Paolo Pasolini em alguns textos da coluna "O Caos", publicada no semanário O Tempo, entre agosto de 1968 e janeiro de 1970. Depois, desdobra-se numa leitura de seu pensamento crítico entre a ideia de "estado de graça", proposta por Christopher Domínguez Michael, e o conceito de "classe", relido e expandido a partir de Walter Benjamin por Andrea Cavalletti.

Palavras-chave: crítica; graça; classe.

Abstract: This article takes start from the critic review of Pier Paolo Pasolini in some of his column The Chaos, published in The Time, weekly newspaper, between August of 1968 and January of 1970. After that, this study unfolds itself in the reading of critical thinking of the ideas of "state of grace", proposed by Christopher Domínguez Michael, and the concept of "class" reread and expanded by Andrea Cavalletti, from the ideas of Walter Benjamin.

Keywords: Critic; Grace; Class.

"A destruição é definitivamente o signo dominante desse modelo de falsa desobediência em que consiste hoje a velha obediência."

(Pier Paolo Pasolini, Corriere della Sera, 18/03/1975)

\section{A FÁBULA DA GRAÇA}

Entre agosto de 1968 e janeiro de 1970, Pasolini escreve uma coluna para o semanário O Tempo, de nome "O Caos", em que imagina projetar

${ }^{1}$ Professor da Escola de Letras e do PPGMS da Universidade Federal do Estado do Rio de Janeiro (Unirio), Brasil: <manoelricardodelima@gmail.com>. 
uma intervenção na luta miúda e cotidiana e lançar-se - um esforço do corpo - numa disposição crítica contra o terror que se instala a partir de qualquer dimensão de autoridade imposta pelo mundo burguês, mesmo que se sinta absolutamente sozinho. Na apresentação da coluna, em 6 de agosto, escreve:

Nesta coluna, uma franja da minha atividade de escritor-para lutar como posso,
e com toda a minha energia, contra qualquer forma de terror, é na verdade
porque estou só. Meu caso não é de indiferentismo nem de independência: é
de solidão (PASOLINI, 1990, p. 37).

Essa solidão de cidadão, segundo ele, adviria de uma ideia da burguesia não apenas como classe social, mas também como uma doença; lê-la como classe seria ideológica e politicamente errado; porque entende que o sistema burguês italiano, o exemplo que tem bem à frente dos olhos, é paleocapitalista e precisamente terrorista e moralista. Diz ele:

Italianos pequeno-burgueses se sentem tranquilos diante de toda forma de escândalo, se esse escândalo tiver atrás de si uma forma qualquer de opinião pública ou de poder; porque eles reconhecem imediatamente, nesse escândalo, uma possibilidade de institucionalização: e se confraternizam com essa possibilidade (PASOLINI, 1990, p. 42).

Semanas depois, no texto de 27 de agosto, acerca de Mondo salvato dai ragazzini [O mundo salvo pelos rapazinhos], livro recém-publicado de sua amiga Elsa Morante, Pasolini (1990, p. 50) defende a ideia de que tem-se aí "um manifesto político escrito com a graça da fábula", além de humor e alegria, sentimentos e tomadas de posição que percebe como incompreensíveis naqueles dias, por causa de um princípio de atomização moral que se dá através do consumo e de um profundo desejo de autodestruição próprio do burguês que se expande numa generalização sintomática, quando ninguém mais está a salvo. É a partir dessa imagem oscilante, porém constituída, que o historiador mexicano Christopher Domínguez Michael vai ler Pasolini: aquele que escreve uma formulação da crítica, ao mesmo tempo, quase histérica, mas também em estado de graça. Essa adversativa é fundamental aí. Assim, o convoca a fazer parte da montagem de uma tríade suspeita diante do avanço do fascismo na Itália durante o século XX: junto a Gabriele D’Annunzio (1863-1938) e Curzio Malaparte (1898-1957), e faz isso a partir das dimensões e das figuras que se enlaçam, separadamente, entre retrato, personagem e fantasma. 
Grosso modo, Domínguez sugere que Pasolini é um verdadeiro homem do renascimento e, também, um incendiário em pantufas (Barth David Schwartz apud MICHAEL, 2016). Entende que, por exemplo, na sua condição de homossexual católico, mesmo que não se possa escrever uma história da sexualidade no século XX à maneira de Foucault, dos gregos aos vitorianos, sem ele, não levou a cabo um verdadeiro enfrentamento com a homofobia da Igreja. Por outro lado, Domínguez argumenta que Pasolini talvez seja o único poeta marxista do século XX, numa linha de começos entre Marx e Gramsci, mas que não vê nessa circunstância um comunista comprometido ou revolucionário, apesar também de sabê-lo muito "interessado na verdadeira vida proletária e na construção de um realismo popular" (MICHAEL, 2016, p. 83), o que Pasolini identificaria, principalmente a partir de seus jovens marginais, tanto com o nacional-popular quanto com um caráter dialetal de uma língua italiana plena de anterioridades. Assim é que aponta o quanto a filologia, para Pasolini, se apresenta, crítica e politicamente, como uma defesa dos dialetos contra a recente destruição produzida pela uniformidade do fascismo, que se atravessa de um novo poder consumista completamente irreligioso, totalitário, corruptor, repressor eviolento, numa vida falsamente tolerante. Daí que faça sentido, mais do que nunca, para Pasolini, a afirmação de Marx segundo a qual o capital transforma a dignidade humana numa mercadoria intercambiável. Ainda mais nesse momento, quando, nesse país, está muito mais em xeque o que se debate ou se debateria em torno da dignidade do que da liberdade.

Em que pese o caráter de uma crítica que se cumpre, segundo Domínguez, entre histeria e estado de graça, é na perspectiva dessa última, não como humor, mas como atenção - tal como a pensava Simone Weil, que $a$ atenção é a atenção que se $\mathrm{faz}^{2}$-, que se pode inverter a proposição que Pasolini projeta sobre o livro de Elsa Morante para inferir outro gesto, outro sentido, ao seu próprio procedimento crítico: de uma graça da fábula para uma fábula da graça. E é com essa postulação equívoca, da leitura de Christopher Domínguez, ao tentar aproximar as tomadas de posição

\footnotetext{
${ }^{2}$ A atenção, afirma Simone Weil (1994), só é se vem antes e depois dela mesma. Antes, porque acolhe o inesperado, o inesperado de uma espera; depois, porque produz uma abertura àquilo que lhe escapa e anula todo centro. A atenção é a atenção que se faz: provar de tudo para pôr-se à prova e, numa mesma ação, confrontar a ideia de forma total que aparece, quase sempre, como visível, na fórmula somática e imperativa de pôr-se em forma. A atenção se dispõe, assim, contra os discursos de instrutor e a retórica de estrutura militar, muito usuais ao nosso redor.
}

Remate de Males, Campinas-SP, v.40, n.2, Pp. 501-510, jul./dez. 2020 - 503 
de Pasolini a um terceiro mundo em sufrágio numa espécie de aceitação de todas as imposições capitalistas, que se abre uma possibilidade para remendar a essa postulação a leitura recente e esperançosa que Alain Badiou faz quando procura reposicionar a ideia de revolução e de revolucionário a partir das revoluções Bolchevique, na Rússia, e Cultural, na China, na pequena reunião de ensaios em Petrogrado, Xangai (2019).

$\mathrm{O}$ apontamento de Badiou é que, basicamente, esses acontecimentos foram mudados na memória dos homens por meio de uma calúnia habilidosa, transformados em fábulas sanguinárias e sinistras. E amplia a questão ao dizer que uma verdadeira revolução é sempre, também, a ressurreição daquelas que a precederam. Daí que, quando se escuta um dizer totalitário, por exemplo, a respeito da revolução russa é importante pensar, automaticamente, que há ali, por trás, mal escondido, um igualitário. Badiou defende a tese de que o ser humano, esse bípede sem penas, é uma espécie recente, e que essas tentativas de revolução não passam de começos ou recomeços da história da espécie humana - a que se ver e ler o que diz Paul Scheerbart, em seu Lesabêndio, 1913, essencial para Walter Benjamin, acerca da fragilidade dessa espécie que se sustenta sobre dois membros tão finos e precários - e recupera a ideia de Marx, a de que os proletários não tem pátria, a sua pátria é a humanidade. E isso para nos lembrar de que

Todos esses jovens que partem do Mali, da Somália, ou de Bangladesh, ou de outros lugares; que querem atravessar os mares para viver onde pensam que é possível viver, coisa que não podem mais fazer em seus países; que se arriscam a morrer centenas de vezes; que têm de pagar atravessadores bandidos; que cruzam três ou dez países diferentes, a Líbia, a Itália, a Suíça ou a Eslovênia, a Alemanha ou a Hungria; que aprendem três ou quatro idiomas, que trabalham ou três, quatro ou dez atividades diferentes. Sim, são eles o proletariado nômade, e qualquer país é sua pátria. São o coração do mundo humano de hoje, eles sabem existir em qualquer lugar onde o ser humano existe. São a prova de que a humanidade é una, é comum. E é por isso que devemos não só acolhê-los como irmãos, mas como uma sorte. E nos organizar com eles para que a humanidade, por fim, comece sua verdadeira vida planetária (BADIOU, 2019, p. 39).

Assim, Badiou afirma que ainda estamos em plena revolução neolítica, naquela em que, entre 15 e 5 mil anos atrás, inventou-se a agricultura sedentária e o armazenamento em cerâmicas para que se pudesse dispor de comida excedente. Disso surgem as classes dominantes ociosas, a existência de estados autoritários, exércitos profissionais, guerras entre nações etc. para nos situar para além dos caçadores-coletores. Em 
seguida, a existência das desigualdades, das hierarquias e das figuras de violência e de poder. Contra essa primeira revolução é que surgem essas outras, segundas, pequenos começos, para nos indicar que ainda estamos num nível pré-político, e que podem, por sua vez, de algum modo, nos lembrar da restituição (tal como pensa Giorgio Agamben: restituir, e não restaurar) da humanidade à sua unidade indubitável, saber sobre seu próprio destino, para liquidar o crime da desigualdade das riquezas e dos modos de vida, porque o capitalismo é a morte. Para Marx, enquanto houver propriedade privada não pode haver felicidade. Desse modo, estamos o tempo inteiro diante da luta de classes e podemos reparar em Lênin dançando na neve porque a revolução bolchevique já durava um dia a mais do que a comuna de Paris, uma vitória; ou de Mao preocupado que, sob o socialismo, a burguesia se refizesse e se organizasse dentro do partido comunista. Numa dilação perversa, a da devoção capitalista, que é uma patologia oriunda de nossos monoteísmos religiosos, essas vacas sagradas, diz Badiou, matamos também essas revoluções ao sacralizarmos seus idealizadores em propensões totalitárias num culto à personalidade, tal qual como fazemos, uma prática cultural, com os grandes artistas. Ele afirma:

\begin{abstract}
Damos importância aos recibos de lavanderia desse ou daquele grande poeta. Se a política é, como creio, e como pode ser a poesia, um procedimento de verdade, então sacralizar os criadores políticos não é nem mais nem menos do que sacralizar os criadores artísticos. Talvez menos, no final de contas, pois a criação política é provavelmente mais rara, com certeza mais arriscada, e se dirige mais imediatamente a todos, em especial àqueles - como os camponeses e os operários chineses antes de 1949 - que o poder em geral considera inexistentes (BADIOU, 2019, p. 83).
\end{abstract}

A partir da rápida inserção dessa esperança de Badiou, se dermos a volta apenas ao empenho da ideia de classe que Pasolini lança sobre a burguesia, por exemplo - a de que seria um erro lê-la dessa maneira -, podemos repisar um desenho que, simplesmente, destitui a linha histérica lançada sobre ele por Christopher Domínguez para que tenhamos, desobrada ou inoperante, a imagem dialética da força que vem do estado de graça entre a atenção e uma linha melancólica - esta que, por sua vez, solicita dizer vagarosa e minimamente por onde e de onde se vem -, reposicionando e alargando a outros empenhos, outros jogos e outros sentidos o caráter do pensamento crítico de Pasolini que, numa antecipação, se desenha mais claro e contundente a partir das estocadas que elabora nos textos para a coluna "O Caos": eis a fábula da graça. 


\section{CLASSE}

O crítico e professor de estética e literatura italiana Andrea Cavalletti, num livro de força em torno do conceito de classe, lido a partir de uma nota de Walter Benjamin, redigida lateralmente para A obra de arte na era da reprodutibilidade técnica (1936), diz, também citando Marx, que:

\footnotetext{
"A grande indústria acumula num lugar uma multidão de pessoas que se desconhecem umas às outras." Aqui, a palavra "lugar" [endroit] não se refere apenas aos muros da velha fábrica; ela dita antes um sentido completamente novo às palavras fábrica, muros, e afirma o princípio segundo o qual o que vale no interior da oficina vale no interior da sociedade [a fórmula de Marx, poder-se-ia arriscar, encontrou no conceito de diagrama abstrato a sua interpretação mais rigorosa] (CAVALLETTI, 2010, p. 112).
}

O ponto de inferência dessa leitura de Cavalletti reabre o sentido e a ideia de lugar, como uma disseminação da fábrica, daquilo que se projeta numa linha-limite entre multidão (as pessoas que se desconhecem umas às outras mas agem impulsivamente a um comum) e coletividade ou, de outro modo, massa e classe. São as leituras que Benjamin desenvolve, por exemplo, a partir de Gustave Le Bon - em A psicologia das multidões, publicado pela primeira vez em 1895 -, quando este diz que não é fácil descrever a multidão, pois a sua organização tem variantes que vão da raça e da composição das coletividades até a natureza e estímulos a que se submetem. Le Bon diz ainda que se tem aí uma dificuldade que se estende também ao estudo psicológico de um ser qualquer. Um agravante é o princípio de poder invencível que se manifesta nos indivíduos inseridos na multidão, por causa da cessão a instintos que alguém sozinho certamente refrearia. A multidão é irresponsável, anônima, e assim tudo que advém dela é difícil de ser detido. Ela incorre em (e impõe) uma contaminação mental, quase uma hipnose, que faz com que um indivíduo altere completamente suas posturas, comportamentos e tomadas de posição quando é levado, muitas vezes, a capacidades e ações, sobre as quais, antes, nem havia pensado.

Benjamin, na referida nota ao ensaio de 1936, expande essa dissensão de Le Bon e a reconfigura, certamente depois de ler o texto de Freud, Psicologia das massas e análise do eu (1921), porque entende que a massa (ou a multidão) a que Le Bon se refere, impenetrável e compacta, é a pequeno-burguesa. O pensador alemão já prenunciara esse apontamento algumas vezes, antes disso - por exemplo em Experiência e pobreza (1933), exatamente a partir da ficção científica de Paul Scheerbart, Lesabêndio 
(1913), e da pintura de James Ensor, com figuras mascaradas formando uma massa compacta e invadindo as ruas de Bruxelas durante um carnaval, a festa da desigualdade absoluta -; e agora a apresenta definitivamente, quando afirma que a pequena burguesia não é uma classe, mas uma massa, e que o proletariado, ao operar a vida através da solidariedade, pode suprimir a dialética contraposição entre indivíduo e massa. Diz ele na nota:

A consciência de classe proletária, que é a mais estudada, modifica radicalmente a estrutura da massa proletária. O proletariado dotado de consciência de classe forma uma massa compacta só quando visto de fora, na representação dos seus opressores. No instante em que se inicia a sua luta de libertação, a sua aparente massa compacta já relaxou, na verdade. Ela deixa de ser dominada pela simples reação; passa à ação. O relaxamento da massa proletária é operado pela solidariedade. Na solidariedade proletária da luta de classes é suprimida a morta e adialética contraposição entre indivíduo e massa; para o camarada ela não existe. Se a massa é assim decisiva também para o guia revolucionário, o seu maior contributo não consiste em deixarse levar atrás das massas, mas em deixar-se sempre reabsorver nelas, para continuar a ser, para a massa, um dos cem mil.

A massa impenetrável e compacta, objeto da psicologia das massas para Le Bon e outros, é a pequena-burguesa. A pequena burguesia não é uma classe; é na realidade apenas uma massa, e tanto mais compacta quanto maior é a pressão à qual é exposta, entre as duas classes inimigas da burguesia e do proletariado. Nesta massa é de fato determinante o momento reativo, de que se fala na psicologia social [...]. Assim, as manifestações da massa compacta revelam sempre, em todo o caso, um traço de dimensão pânica - exprima-se nelas o entusiasmo bélico, o ódio contra os judeus ou o instinto de autoconservação (BENJAMIN, apud CAVALLETTI, 2010, várias páginas). ${ }^{3}$

Essa dimensão pânica a que Benjamin alude é aquela que Le Bon denominava prestígio e que faz parte de um fenômeno habitual de todas as estruturas de mercado e consumo da modernidade do capitalismo, este parasita indômito, que vai desde os produtos mais simples da feira ou do supermercado até, principalmente, as estruturas simbólicas da cultura. Eé daí que advém o fascismo, exatamente, diz Cavalletti (2010, p. 6o), porque a pequena burguesia, para Benjamin, não é uma classe, e desta "não-classe é que todo o fascismo produzirá o seu 'povo', mascarando a pura e simples compreensão nos nomes arcaicos e inseparáveis de comunidade, pátria, trabalho, sangue, chefe". E prossegue:

3 Tentei redigir a nota de Walter Benjamin a partir de uma série compilada de citações feitas por Andrea Cavalletti (2010) no seu livro Classe (edição portuguesa). 
A multidão que, segundo Le Bon, adquire uma consciência deformada, mas a seu modo plena, no leader prestigioso, não era, na verdade, senão uma massa latente de chefes, ainda não conscientes, mas prontos a emergir. A consciência de classe revolucionária é, porém, uma condição-limite. Aqui, todo guia se perde na massa e é até duvidoso, segundo Benjamin, que se possa ainda usar esta palavra: "consciência" - que melhor se adequa à mercadoria (CAVALLETTI, 2010, p. 60).

Diante de um mundo que gira em torno do dinheiro, que é gerado e gera todo artefato de sentido a partir do e com o dinheiro, a causa comum passa a ser apenas um motivo perverso dos usos de uma ideia de consciência: o da organização de uma multidão fascista que tende à felicidade desesperada numa sociedade homogênea que pode ser figurada, por exemplo, nos contornos vertiginosos, ressentidos, soturnos e violentos do flâneur - esta ilusão que nos engana a todos, também já apresentada por Benjamin em sua leitura de Charles Baudelaire. E é esse projeto fascista, entre voltas e reviravoltas, uma espécie de sem saídas, que Pasolini denuncia o tempo inteiro tomando como referência a sua Italieta quando, para ele, sem exceção, todos querem as mesmas coisas e se comportam da mesma maneira.

Na última entrevista, a Furio Colombo, numa tarde de primeiro de novembro de 1975, entre 16 e 18 horas, pouco antes de ser assassinado neste mesmo dia, à noite, Pasolini (1990, p. 245) conclui: "Talvez eu esteja enganado. Mas continuo afirmando que estamos todos em perigo". Tanto que no dia 8 de novembro daquele ano, a entrevista é publicada com esse título preciso: "Siamo tutti in pericolo". Seu questionamento mais severo e radical parte da afirmativa de que há uma ilusão violenta que vem da multidão, da escola, da televisão, da placidez dos jornais e do que ele toma como conservadores de uma ordem terrível numa busca incessante por poder, qualquer poder, o qual sempre se baseia nas ideias de posse $e$ destruição ou, às avessas, numa "série dos inevitáveis contragolpes de uma luta mais geral - mas também por poder" (PASOLINI, 1990, p. 177).

Como escapar à ideia de que um acontecimento só é quando se torna uma notícia, elaborada, montada e titulada; como desmontar e enganar a fábrica; como desmontar e enganar o mapa; como desmontar e enganar a arte; como escapar e criar uma esquiva, por exemplo, ágil e deliberada, de que aquilo que se instala no corpo - como uma ideia da matéria, nosso limite com a linguagem - só tem existência se pode ser dito, se pode ser falado, se há para isso uma palavra, aquilo que engendraria alguma imagem e o que tomamos como real? Assim, se estamos todos 
em perigo, rapidamente, associamos numa percepção equívoca o perigo à normalidade numa espécie de trégua perene. Talvez porque estamos diante de uma guerra e, diante de uma guerra, nos transformamos, sem a inferência vigorosa da metamorfose, em técnicos da guerra, pequenos seres plenos e fazedores de mapas, de cartografias, de diásporas fixas, repetitivas e fajutas, técnicos de um sistema que, numa dimensão nociva, completa e monopolizadora, passamos a chamar de mapas afetivos ou de sistema para uma cartografia de possíveis. Isso é outro contrassenso, mas é a oscilação dessa imagem que funda a modernidade para um desenvolvimento mímico e unânime, e impede o corpo de qualquer possibilidade de avanço com alguma experiência. E Pasolini, com força e numa tomada de posição radical, imagina ou questiona acerca do que ainda pode engendrar um pensamento com o corpo. Diz ele que é como quando chove e os bueiros estão entupidos:

A água sobe, uma água inocente, de chuva, que não tem a violência do mar nem a crueldade da correnteza de um rio. Entretanto, por uma razão qualquer, ela não desce, mas sobe. [...] Vejamos como é que se desentope esse maldito tanque, antes que acabemos todos afogados (PASOLINI, 1990, p. 243).

Daí que se possa recuperar um outro aviso de Pasolini, ao responder a Italo Calvino, numa carta aberta, publicada no Corriere della Sera, em 1o de março de 1975, afirmando que o fascismo nasce da escolha (da consciência) que uma maioria silenciosa (a multidão) faz entre a sacralidade da vida e os sentimentos, de um lado, e o patrimônio e a propriedade privada do outro. Por isso que, para Benjamin, tal como é para Pasolini, consciência é aquilo que melhor se adequa à mercadoria. E por isso ele sugere, sem trair uma tradição intelectual humanista e racionalista, que "não se deve ter medo, como exatamente há um tempo atrás, de ter um coração” (PASOLINI, 1990, p. 198), essa fábula da graça quando a atenção é a atenção que se faz.

\section{$\overline{\text { REFERENNCIAS }}$}

BADIOU, Alain. Petrogrado, Xangai: as duas revoluções do século XX. Trad. Célia Euvaldo. São Paulo: Ubu, 2019.

BENJAMIN, Walter. O anjo da história. Trad. João Barrento. Lisboa: Assírio e Alvim, 2010.

BENJAMIN, Walter. Linguagem tradução literatura. Trad. João Barrento. Lisboa: Assírio e Alvim, 2015. 
CAVALLETTI, Andrea. Classe - uma ideia política sob o signo de Walter Benjamin. Trad. António Guerreiro. Lisboa: Antígona, 2010.

LE BON, Gustave. Psicologia das multidões. Trad. Mariana Sérvulo da Cunha. São Paulo: Martins Fontes, 2016.

MICHAEL, Christopher Domínguez. Retrato, personaje y fantasma: D’Annunzio, Malaparte y Pasolini. Ciudad de Mexico: AI Trani, 2016.

PASOLINI, Pier Paolo. Jovens infelizes - antologia de ensaios corsários. Trad. Michel Lahud e Maria Betânia Amoroso. Org. Michel Lahud. São Paulo: Brasiliense, 1990.

PASOLINI, Pier Paolo. Caos - crônicas políticas. Trad. Carlos Nelson Coutinho. São Paulo: Brasiliense, 1982.

Recebido: 7/5/2020

Aceito: $13 / 8 / 2020$

Publicado: $30 / 11 / 2020$

Remate de Males, Campinas-SP, v.40, n.2, pp. 501-510, jul./dez. 2020 - 510 